\title{
The Process of Validity and Reliability for Verbal Questioning Research in the Classroom
}

\author{
Zanaton H Iksan (Corresponding author) \\ Faculty of Education, Universiti Kebangsaan Malaysia \\ 43600, Bangi Selangor, Malaysia
}

Tel: 601-9-600-4627Ｅ-mail: zanaton.iksan@ukm.edu.my

\begin{abstract}
Md Noor Saper
Faculty of Education and Human Development, Universiti Pendidikan Sultan Idris 35900 Tanjung Malim, Perak, Malaysia
\end{abstract}

Tel: 0601-9-222-4627Ｅ-mail: md.noor@fppm.upsi.edu.my

Received: December 20, 2015 Accepted: February 19, 2016 Published: March 15, 2016

doi:10.5296/gjes.v2i1.8755 URL: http://dx.doi.org/10.5296/gjes.v2i1.8755

\begin{abstract}
In any research approach, data obtained should be reliable and authentic in order to make sure that the results are valid. In qualitative approach too, even though the process of data collection was carried out as outlined and discussed in detail by expert researchers in this area, the experiences of the researcher during the process were different and should be shared with other researchers. The objective of this study is to discuss on the process of obtaining validity and reliability in the process of conducting qualitative research about verbal questioning during the teaching and learning. The findings discuss on six types of process to ensure that validity and reliability is achieved, which are: triangulation, prolonged engagement, member checking, peer review, an audit trail and researcher's bias. This impact of this study inform that the several techniques for getting validity and reliability of the data collection are needed to ensure that the findings of research are reliable and authentic.
\end{abstract}

Keywords: Validity, Reliability, Triangulation, Prolonged engagement, Member checking, Peer review, Audit trail, Researcher's bias 


\section{Introduction}

The elements of validity and reliability in a research utilizing the qualitative approach are two very important factors in ensuring that the research is conducted utilizing the correct process. This process could also reinforce the findings of a research, ensuring that the findings are valid and reliable. It shows the extent to which the findings reflects the phenomenon being studied or explored is accurate and consistent (Othman, 2006). Even though it is difficult to achieve validity and reliability since the qualitative research approach is utilized in an existing and natural phenomenon, it could be achieved through an organized and ethical data management (Merriam, 2001; Wiersma, 2000). Both validity and reliability could also be achieved through detailed presentation or narration of the steps taken by the researcher in the research process (Bailey, 2007). In conclusion, validity and reliability could explain how research findings could be supported by solid evidence which leaves no room for doubt.

The validity and reliability processes for a research are probably different, depending on the research context. Therefore, the objective of this article is to discuss the researcher's experience in the process of achieving validity and reliability for a research regarding verbal questioning practice during the teaching and learning process. The discussion of the validity and reliability process in this verbal questioning research utilized the triangulation process, prolonged engagement, member checking, peer review, researcher's bias and audit trail.

\section{Validity and Reliability}

Validity refers to the measurement of research accuracy in which the research provides a true picture of the research subject (Bailey, 2007; Othman, 2006). According to Merriam (2001) validity is related to how the research findings match the true reality. On the other hand, the reliability is refers to the extent in which the research findings could be repeated to produce the same result (Merriam, 2001). Wiersma (2000) states that this could be obtained through continuous collection process using various methods.

\section{Research Methodology}

The data is collected through observation, interview and document analysis. These data collection techniques were chosen and are suitable since this approach allows for an in-depth study to be conducted for a particular event, activity and process (Creswell, 2003). Additionally, this approach focuses on the natural state in which the event took place in a true environment and condition (Marohani Yusoff, 2001; Meriam, 2001; Miles \& Huberman, 1994). Therefore, this approach is capable of producing rich data and information through the processes of observation and in-depth interview based on the observation done by the researcher while at site.

The data was in the form of dialog between teacher and students during the teaching and learning process in the classroom. So, the main data in this research is the teacher's teaching verbatim data. Teacher's teaching verbatim is based on the teacher's teaching and learning process which contain teacher's verbal question, teacher and student's behaviour, sutdents' response, teacher's feedback, waiting time notes and researcher's observation notes. In this reasearch context, verbal question refers to the statement in the form of a question which 
contains the words what, when, who, where, why, how and how many; the statement made in the intonation of a question; the statement with the word ' $k a h$ ' (In Malay language); the statement in the form of an instruction or direction which requires verbal answer; the statement with yes or no answer; and statement in the form of an affirmation or validation such as correct? Right? (Nor Razah Lim \& Zamri, 2007). An example of teacher's teaching verbatm is given in Appendix 1.

The subjects are five chemistry teachers and the verbal questions focused on the topic of Electrochemical (Form Four's chemistry lesson). Three teachers are from three different schools and two teachers teach at the same school. Four schools are involved in the this research and all schools are located in the same district.

\section{Research Findings and Results}

This article discusses six types of processes utilized to achieve data validity and reliability. The discussion of each process is focused on the research involving verbal questions during the teaching and learning process. These validity and reliability processes are:

\subsection{Triangulation}

Triangulation refers to the utilization of various data sources, research, data collection method and analysis (Bailey, 2007; Merriam, 2001; Othman, 2006). Heath (2015) mention that triangulation is the use of multiple measures to capture a construct. The utilization of all these techniques allow for a better and more reliable way to verify the findings. Modell (2009) critique on the use of triangulation in mixed method based on two paradigms; functionalist and interpretive. Additionally, the techniques could enhance the validity and reliability of the findings since each data obtained from one particular technique could be enhanced by another techniques.

In this study, the triangulation technique is utilizes between methods and within method. Triangulation between methods is carried out utilizing various data collection technique. The researcher has conducted a "non-participating" observation in a few teaching session of certain topics. Data collection through observation produces the teacher's teaching verbatim data which contains dialog between teacher and students (teacher-students dialog) and observation notes. Both of this information are parallel and reinforce each other. The dialogues could trace the teacher's questions to engage students' knowledge related to the concept learned (Iksan \& Denial, 2015). For example, teacher-student dialog shows that the teacher asked the verbal question by calling a student's name (Fakih), as in the following dialog: showed that the teachers started the lesson with questions to engage students' knowledge related to the electrochemistry concepts.

Teacher: Okay, (3) Can you remember the properties of the ionic compound? (MP3:1.55-2.14=0.59). Okay, Fakih! (4) Can you remember the properties of the ionic compounds?

Fakih: (stand up and answer) "dissolve in water"

[N,4B,P1(200608)/14-22]

Observation data is obtained by making field notes which is parallel with the above information. 
"After asking a verbal question, the teacher waits for the students to respond no response - and repeat the question. Teacher wait for the students to respond again, but there is still no respond, the teacher called Fakih and repeat the question"

[N,4B,P1(200608)/27-29]

The researcher then analyzed the teaching verbatim and this is followed by and interview based on the above observation. This is done by establishing an interview protocol which is parallel with the teacher-student dialog and the above observation to obtain further information regarding why that particular student was called. The following interview is to obtain further information regarding the above observation:

Researcher:Verbal question 1 to 4, you repeated the verbal question a few times, pause and then you called a student's name, why?

Teacher: We usually give the students time to think ... so that they could think of the answer to be given ... sometimes we might feel that the verbal question is easy, but to the students it is a difficult question ... and we want them to think ... the thinking process takes some time, sometimes we may give them 2-3 minutes to think of the answer, and then we ask the question to the students, meaning that all students have given it a thought, haa ... we want all students to think because if we ask a verbal question quickly and call Ahmad, ha .. the other students will not think of the answer, or if we say after him, you will answer, and then you will answer, he would answer sometimes ... haa ... those who have given the answer would not think of the answer anymore, those who have not answered the question would be thinking of the verbal question he wants to answer only, so that what it is usually like.

[N,TB6(270209)/190-200]

The triangulations which form within method were carried out in this research. This is done by making repeated observation and interview with each subject. This process shows that the teacher repeated the same behavior over and over again. This makes the findings of the study credible beyond doubt. The same thing occurs during interview, in which the teacher stated the same thing by giving examples or repeating what have been said in previous interview.

Triangulation utilizing both methods (between methods and within method) could increase data reliability since data evaluation and examination could be done by comparing the data collected from various sources (Merriam, 2001).

\subsection{Prolonged Engagement}

Prolonged engagement means that the researcher is in contact with the subjects over a long period of time. Merriam (2001) states that a prolonged engagement is achieved by repeating data collection of the same phenomenon over a long period at the site (long-term observation) in addition to maintain continuous relationships with subjects. In this way, the prolonged period provides the researcher with the opportunity to conduct repeated observations and 


\section{MlMacrothink}

Global Journal of Educational Studies

ISSN 2377-3936 2016, Vol. 2, No. 1

interviews, gain the trust of the research subjects, establishes a good relationship so that the research subjects feel comfortable in providing information (Othman, 2006). Creswell (2003) states that prolonged engagement is necessary right from the early stage, before the actual data collection. During this early period, the researcher could get to know the classroom and school culture, get to know and build relationship with study participants and build rapport. However, in this study, the researcher was not able to be at the school at all times since the researcher had to allocate time to go to other schools for a short period of time in one day. The researcher does, however, go to the schools often to meet up with the teachers during free period and is always in contact with the teachers by telephone and SMS. This could alsoimprove the relationship between the researcher and the teachers.

The planned prolonged study period is to take into account the school calendar which involves activities such as sports day, excursion, parents-teacher meeting and other unexpected events so as to ensure that the study does not interfere or impose on subjects. All these activities take a long time and are most probably carried out during school hours. The researcher might not be able to conduct in-class observation according to schedule or conduct interview even though this study requires that the teaching and learning process in its true meaning be carried out in the best possible way. In this study, the prolonged engagement is achieved by making a number of observations during the teaching session for a particular subject, which is then followed by an interview with each study subject. Table 1 shows the dates the data were collected for observations and interviews.

Table 1. Data collection date for observation and interview

\begin{tabular}{|c|c|c|c|c|}
\hline \multirow{2}{*}{ Study subject } & \multicolumn{2}{|c|}{ Observation } & \multicolumn{2}{c|}{ Interview } \\
\cline { 2 - 5 } & No. & Date & No. & Date \\
\hline Nora & 1 & 20.06 .08 & 1 & 24.06 .09 \\
\hline & 2 & 24.06 .08 & 2 & 22.07 .08 \\
\hline & 3 & 11.07 .08 & 3 & 18.09 .08 \\
\hline & 4 & 15.07 .08 & 4 & 15.10 .08 \\
\hline & & & 5 & 12.02 .09 \\
\hline & & & 6 & 27.02 .09 \\
\hline Roha & 1 & 18.07 .08 & 1 & 10.06 .08 \\
\hline & 2 & 25.07 .08 & 2 & 04.05 .09 \\
\hline & 3 & 06.08 .08 & 3 & 13.05 .09 \\
\hline & 4 & 07.08 .08 & & \\
\hline Rosni & 5 & 08.08 .08 & & 25.06 .08 \\
\hline & 1 & 10.07 .08 & 1 & 17.10 .08 \\
\hline & 2 & 17.07 .08 & 2 & 27.04 .09 \\
\hline & 3 & 18.07 .08 & 3 & \\
\hline & 4 & 24.07 .08 & 4 & \\
\hline
\end{tabular}




\begin{tabular}{|c|c|c|c|c|}
\hline Salina & 1 & 07.07 .08 & 1 & 22.07 .08 \\
\hline & 2 & 14.07 .08 & 2 & 14.10 .08 \\
\hline & 3 & 21.07 .08 & 3 & 09.04 .09 \\
\hline & 4 & 24.07 .08 & 4 & 10.04 .09 \\
\hline & 5 & 28.07 .08 & 5 & 20.04 .09 \\
\hline Zai & 1 & 09.07 .08 & 1 & 30.07 .08 \\
\hline & 2 & 16.07 .08 & 2 & 05.11 .08 \\
\hline & 3 & 18.07 .08 & 3 & 22.09 .08 \\
\hline & 4 & 30.07 .08 & 4 & 21.04 .09 \\
\hline
\end{tabular}

This study involves two phases of data collection in a period of approximately twelve months (one year). The first phase involves observations conducted repeatedly in a period of three months beginning June 2008 until August 2008. The second phase involves data collection through interview. However, some of the interviews were conducted concurrent with the observations done during the first phase. The interviews conducted during the first phase are general interviews and did not focus on a particular observation due to the time constraint of participant and the lack of time to prepare teacher's teaching verbatim.

Most of the interviews were conducted concurrent with the analysis of observation data which involved in-depth interview, i.e. exploring the teacher's verbal questioning practice which was obtained from teaching verbatim. Data collection of the interviews was conducted until May 2009. It is hoped that this period is sufficient to find the answers to the study question in order to obtain an overview of the verbal questioning practice and process among the subjects.

An in-depth interview was conducted after analyzing the teacher's teaching verbatim. During the data analysis process, the researcher was not in the field or at school. However, the researcher was always in contact with the subjects to obtain information as well as to build rapport. Data collection through interview was done by making an appointment with a particular participant to ensure convenience in order to obtain accurate and concise information. To avoid causing inconvenience during school hours, all subjects agreed to allow the researcher conducted the interview either at home or after school hours. In short, the prolonged period was to ensure that in-depth information was obtained as well as to avoid the various constraints that might arise if the interview was conducted at school. This is crucial to avoid causing inconvenience to the subjects some of whom are involved in the school administration.

\subsection{Member Check}

The member check includes data examination and interpretation to be referred again to the subjects to allow them to verify the accuracy and truth of the information and study report (Merriam, 2001; Othman, 2006). This is not only to test the accuracy and validity of the data, but also to provide evidence which would enhance the credibility and reliability of the findings. Although the researcher did everything to ensure her role as the main study 
instrument, bias which might influence the data could occur (Miles \& Huberman, 1994). In addition, error in data collection might occur due the researcher's vague understanding or misunderstanding of the true situation. In order to minimize this situation, the researcher gave the subjects the opportunity to go through and read the data obtained.

In this research, member checking is done in three stages. In the first stage, validation of the transcription is made; the second stage is the verification of the researcher's understanding and interpretation; and in the third stage, several categories and theme formed by the researcher is verified. The validation of transcription is done for raw data, i.e. teacher's teaching verbatim which contains the dialog between the teacher and the students as well as observation notes. Additionally, interview data transcription was also verified. The researcher gave the raw material (teaching verbatim transcription and interview transcription) to the subjects along with a validation form to be signed as proof of verification. This allows the study subject to give feedback either by adding or eliminating, commenting, or making improvement if there was confusion or inaccuracy in the information. The Subjects were also given the opportunity to eliminate data if necessary. Figure 1 shows an example of the correction done by the study subject.

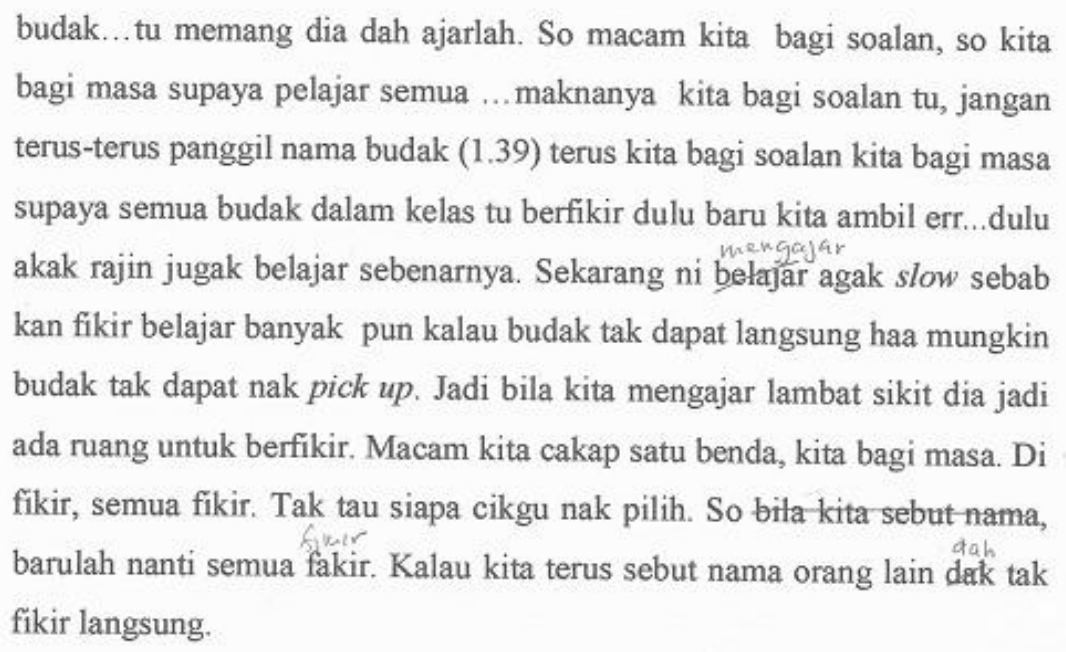

Figure 1. Changes made by study participant

The returned transcript was then improved on based on the correction made by the subjects. All subjects gave their cooperation in reading, correcting and also verifying the raw data. Some subjects gave their comments in their discussions with the researcher and clarified what they meant at the time to avoid spending too much time on it. Some of them gave their comments a week after the data were given to them. The teachers need this extra time so that they would have enough time to give a good review and comment.

The verification of understanding and interpretation was done to gain a better understanding of a particular thing that was not well understood. At the same time, the researcher also asked 
for input regarding how far the accuracy of sentence reported by the researcher was consistent with what was meant by the subjects. This was done by asking for further explanation regarding the things were vague and not well understood, and also by obtaining verification of the assumptions made by the researcher. This was done when the researcher conducted further interview session. The quote below is an example of the researcher's effort to understand a particular phenomenon:

Researcher Why do you insist that the student answered?

Teacher We tried to get him to answer ... we want him to give the answer ... meaning that he think of the answer to give ... sometimes when we give the answer ... the students can't answer, and they feel inferior ... which is why sometimes we can't ask a difficult question to weak students ... which is why he doesn't want to learn ... and he feels weak ... he is afraid to ask questions ... he's shy ... because when we ask a question it involves the student's self-esteem ...

Researcher I'm interested in self-esteem ... what do you mean by self-esteem?

Teacher It means that when we ask the question ... it means that we can't ask difficult questios to weak students ... we already know they will not be able to answer the question ...

Finally, the subjects verify a number of categories and themes formed by the researcher. This was done through discussions and by asking for input regarding a number of categories and themes formed to get confirmation from the subject's perspective. The quote below is an example of what the researcher did to obtain verification and further understanding of the student variability category.

Researcher Regarding the asking of questions, for a number of questions, i.e. no 8,9, you asked the question in English followed by a translation in Malay in the same form, what are the advantages?

Teacher The advantages are, if the student doesn't understand English, he is able to understand in Malay .. or sometimes we ask the question not to one particular student, but to the whole class ... and in one class, some students speak English well, while others do not master the English language well, and there are those who don't really listen. So when we repeat the question in Malay there are three groups that need to understand the question ... first, those who can understand English, second those who don't understand English, and third those who did not listen. So we repeat the question so that the student can hear it, and understand the question. 
Researcher This means that you take into consideration the different categories of students ... so what is the variety of students in this class like?

Teacher In classroom context there are some students who have problems in understanding English, although they may understand but they may not be able to understand some things or take a bit of time to understand ... the second thing is our pronounciation ... the students may misinterprate what we say ...

All these process could reinforce researcher's confidence in the analysis process and the formation of themes and categories. This is to ensure that the data collected were from the subject's perspective.

\subsection{Peer Examination/Peer review}

High-quality research requires a great emphasis on the role of the peer review process (Zaharie \& Osoian, 2016). Peer review is data review for the purpose of evaluation either by colleagues or those who have been involved in research or a phenomenon being studied (Merriam, 2001; Othman, 2006). This process provides opportunities to put forth sound ideas regarding the themes and categories formed as study findings.

In this study, peer reviews were carried out in three ways, i.e. discussion with supervisor, informal discussions with fellow students and formal discussions. In the first method, the researcher had a number of discussions with the supervisor throughout the study and the focus is in the data analysis process. The purpose of this discussion was to obtain a picture of the analysis process and the theme formed since the supervisor was also involved in the teaching and learning process.

Additionally, the researcher also had informal discussions with fellow students, especially those utilizing the qualitative approach and at the same time were involved in the teaching process, i.e. they were teachers. Since this research involves the process of teaching and learning, it relatively easy for the researcher to discuss with fellow students who will eventually be involved in the teaching field.

Finally, the researcher had two formal discussions, on 2 June 2009 and 20 June 2009. These discussions were attended by the supervisor and three colleagues who have experience in the teaching of science. The purpose of this discussion was to enhance the validity of the findings in the form of categories and themes formed by the researcher in the analysis process. In this discussion, the researcher provided copies of the data and the arising themes as well as the quotation for each theme. The themes were organized using the NVivo 8 software, in which each arising theme was accompanied by reference to facilitate the search from raw data. Also, these themes were defined to give a picture of what was meant by the researcher to facilitate the process of verification.

This process was carried out to seek the opinion of other parties as well as to ask them to review the tentative categories and themes formed by the researcher. Hence, Chan (2016) 
mention that the peer reviewers should bring an outsider views on understanding about the theme findings and discussions. This was to ensure that the themes formed by the researcher were accepted as research findings after receiving critics through the collaboration of the researcher and with other researchers. The formation of themes in this way was sounder because it was done two-way. This process provides a venue for question and answer, and discussion to understand the context of study. For example, after I presented the arising themes, the discussion opens for my colleagues to ask how such themes arise. The researcher then gave explanation based on the context or phenomenon that took place by referring to the teaching verbatim and interview data.

\subsection{Audit Trail}

Audit trail is a detailed explanation process regarding how the data was collected, how categories and themes are formed, and how results are obtained through investigations (Merriam, 2001). Audit trail is also formed by documenting the processes of writing journals and memo, keeping logs of all activities carried out, keeping a chronology of data collection, and clearly recording the data analysis procedure (Othman, 2006). In this way, the researcher is able to track the thinking, prediction, and intuitive ideas throughout the data analysis process right from the very beginning. Audit trail is also a data auditing process to facilitate the searching and tracking of events that take place in the field. This process provides the opportunity to obtain findings that are valid and reliable.

In this research, the audit trail process was conducted in several ways, i.e., writing down all daily activities relating to data collection up to the findings of the study. The researcher also had a log book to document the data collection chronology and data storage in a computer system which keep tracks of dates, time and provide an index for every type of data collected.

Furthermore, audit trail process was also done during the writing of thesis. This is done by writing the index and numbering to state the source for all data in the form of quotations which were used as evidence in the findings of the study. For example N,4B,PI(260608)34/40 means that the quote was from Teacher Nora's data during the first observation session in Class 4B on 26 June 2008 and the quote was from line 34 to 40 . The clarity of this reference was to track and re-access the original data. The audit trail process indirectly enhances the validity of data.

\subsection{Researcher's Bias}

Researcher bias is the researcher's ability to explain the assumptions made in the early stage of a research (Merriam, 2001). Othman (2006) is of the opinion that researcher's bias is a procedure in which the researcher is able to explain the assumptions, believes, values and bias which may influence the research. This is necessary to enables the reader to understand his position to reduce researcher's bias in a research process. In this research, the researcher reduces bias by avoiding making her own assumptions by justifying the things that were noted down to avoid any biased evaluation. For this purpose also, the researcher has given detailed explanation regarding the background of the subjects, and elucidate the phenomenon or natural context in discussing an arising theme as the findings of the study. The research 
also has to give detail background based on the research context for example state the time for the research about questioning because wait time is one of the element in it (Iksan \& Daniel, 2016)

\section{Conclusion}

The process discussed above relates to how a research utilizing the qualitative approach must go through a validity and reliability process. This is to ensure that the findings of the research are credible and highly valid. This article has discussed six processes to obtain validity and reliability based on the study questioning during teaching and learning process. Each process has its own procedure to provide the proof of validity for a particular finding. Some of these processes may overlap or are parallel with each other. This phenomena, however, is not weakness in the validity and reliability process, instead they reinforce the findings. In conclusion, the validity and reliability process is necessary to prove that the findings are truly valid and reliable. This proof, in turn, will be able to convince other researchers to utilize the findings if the context or phenomenon put forth in the discussion of the findings are similar. Therefore, research utilizing the qualitative approach can be used in the same context even though it cannot be generalized in a wider population. There are so many things that humans need to explore. And the qualitative approach is more superior way in making an in-depth exploration of these things and in different context.

\section{Acknowledgement}

This work was supported by Action and Strategic Research Grant, Universiti Kebangsaan Malaysia [grant number: UKM-DIPM-010-2011].

\section{References}

Bailey, C. A. (2007). A guide to qualitative field research (2nd ed.). London: Pine Forge Press. http://dx.doi.org/10.4135/9781412983204

Chan, Z. C. Y. (2016). Student peer Reviewers' views on teaching innovations and imaginative learning. Nurse Education Today. http://dx.doi.org/10.1016/j.nedt.2016.02.004

Creswell, J. W. (2003). Research design: Qualitative, quantitative, and mixed method approaches. London, UK: Sage.

Heath, L. (2015). Trangulation: Methodology. International Encylopedia of the Soial \& Behavioral Science (Second 6dition), 639-644. http://dx.doi.org/10.1016/B978-0-08-097086-8.44059-6

Iksan, Z. H., \& Daniel, E. (2015). Emerging Model of Questioning through the Process of Teaching and Learning Electrochemistry. International Education Studies, 8(10), 137-149. http://dx.doi.org/10.5539/ies.v8n10p137

Iksan, Z. H., \& Daniel, E. (2016). Types of Wait Time during Verbal Questioning in the Science Classroom. International Research in Higher Education, 1(1), 72-80.

Marohaini, bt. Y. (2001). Pengutipan dan pengumpulan data perlakuan dan proses menulis 


\section{Macrothink}

Global Journal of Educational Studies ISSN 2377-3936 2016, Vol. 2, No. 1

karangan dalam bilik darjah. In. Penyelidikan kualitatif: Pengalaman kerja lapangan kajian (pp. 87-120). Kuala Lumpur: Penerbit Universiti Malaya.

Merriam, S. B. (2001). Qualitative research and case study applications in education. San Francisco, CA: Jossey-Bass.

Miles, M. B., \& Huberman, A. M. (1994). Qualitative data analysis (Edisi ke-2). London: Sage.

Modell, S. (2009). In defense of triangulation: A critical realist approach to mixed methods research in management accounting. Management Accounting Research, 20, 208-221. http://dx.doi.org/10.1016/j.mar.2009.04.001

Nor, R. L., \& Zamri, M. (2007). Peningkatan kualiti penyoalan guru Bahasa Melayu dalam meningkatkan kemahiran berfikir pelajar. Prosiding Seminar Kebangsaan Isu-isu Pendidikan Negara Ketiga, 67-78.

Othman, L. (2006). Penyelidikan kualitatif: Pengenalan kepada teori dan metod. Tanjung Malim, Malaysia: Penerbit Universiti Pendidikan Sultan Idris.

Wiersma, W. (2000). Research methods in education: An introduction (7th ed.). Boston: Allyn and Bacon.

Zaharie, M. A., \& Osoian, C. L. (2016). Peer review motivation frames: A qualitative $\begin{array}{llll}\text { approach. } \quad \text { European } \quad \text { Management } & \text { Journal, }\end{array}$ http://dx.doi.org/10.1016/j.emj.2015.12.004

\section{Copyright Disclaimer}

Copyright for this article is retained by the author(s), with first publication rights granted to the journal.

This is an open-access article distributed under the terms and conditions of the Creative Commons Attribution license (http://creativecommons.org/licenses/by/3.0/). 